\title{
Editorial
}

\section{Key areas of research at the Department of Production Technology}

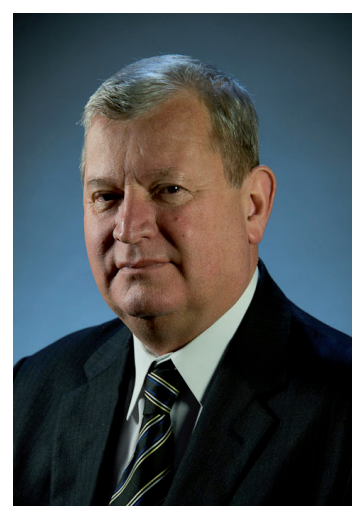

\section{prof. Ing. Peter Demeč, CSc.}

Head of the Department of Production Technology, Technical University in Košice, Faculty of Mechanical Engineering, Institute of Design and Process Engineering

Manufacturing machines and devices are involved in creating virtually every product. The main developmental trends in machine tool construction stem from customers' demands to shorten the production process in all its phases. For the machine tools design, this is an increasing demand for machine dynamics while maintaining their high working accuracy, flexibility and machine re-configurability based on modularity principles. Are being sought a new kinematic structures of machines, light and rigid constructions of moving machine nodes. Considerable time savings can be achieved at the development stage of the new machine by eliminating the need to manufacture its prototype, and the properties of the newly engineered machine are verified in its simulation models. This principle of so-called virtual prototyping is supported by the existence of powerful hardware, but also by perfect software products. The development of methods of virtual prototyping of machine tools and the research of non-traditional kinematic structures of machines belongs among the key areas of scientific and research activities of the Department of Production Technology. The following projects have been successfully resolved over the years:

- Grant project VEGA 1/0478/10: The research of machine tools' working accuracy improvement using numerical simulation of the cutting process dynamics (2010 - 2011). The scientific project was focused on the research of principles and development and verification of the virtual machining methods of virtual workpieces on virtual machine tools. Therewere developed methodologies forcreating the digital models of selected types of machine tools with a focus on simulating their working accuracy and the possibilities and principles of mathematical modelling of the virtual machining process on the virtual machine with definitions of characteristic workpieces and characteristic operations for selected types of machine tools were examined. In addition, methods of quantification of machine tools working accuracy were developed on the basis of the results of virtual machining of characteristic workpieces, numerical experiments were carried out and their verification on real machines followed by specification of the proposed simulation models.

- Grant project VEGA 1/0854/12: Research and development of new kinematic structures based on rotary modules for use in construction of manufacturing machines and robots (2012 - 2014). The research project was focused on the research and development of new kinematic structures based on newly developed and patented rotary modules for use in the construction of production machines and robots. Realized was research of options the replacing of linear motion units in the building of production machines and robots by rotary modules. Were performed analyzes of static, kinematic, dynamic and accuracy parameters and the working area of the machine with unconventional kinematic structure. Research on new kinematic structures was realized by combining of virtual prototyping 


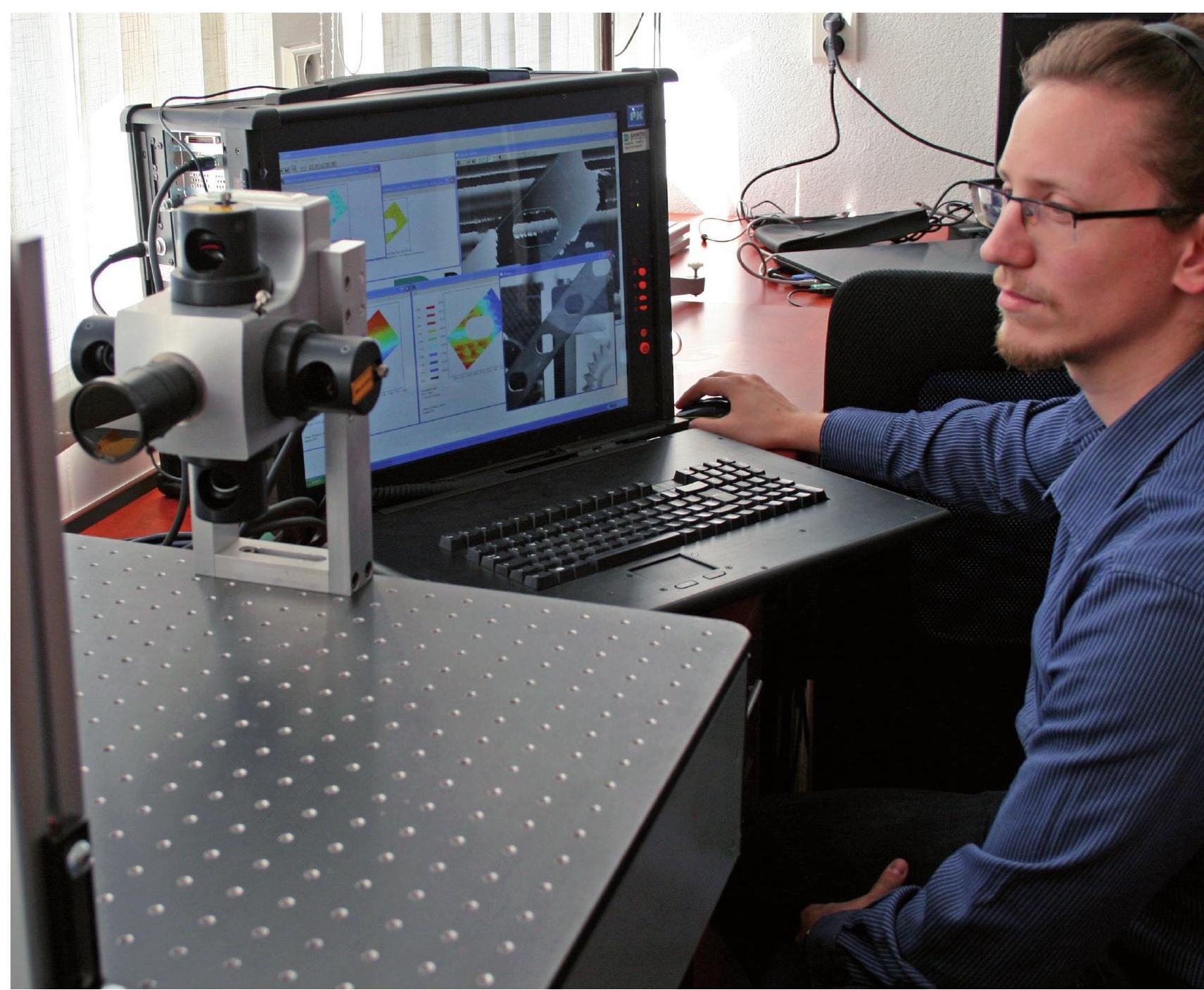

and verification of analytical solutions to a specially developed experimental prototype of machine.

- Grant project VEGA 1/0124/15: Research and development of advanced methods for virtual prototyping of manufacturing machines (2017 - 2017). The scientific project was focused on research and development of advanced methods of virtual prototyping of production machines. The leitmotif of the project was the research of the possibilities of creating the complex digital virtual models of production machines, which are able to describe both the mechanical structure of the machine and its control and eventually also the real control system, which is considered in the design. The research and development of new advanced virtual prototyping methods was carried out by a combination of FEMbased analytical methods, modelling of accuracy characteristics of the machine tool, simulation of control and verification of analytical solutions on a specially developed experimental prototype of a model three axis machine tool based on a modular concept. The project also addressed the question of possible areas of utilization of the innovative potential of advanced virtual prototyping of production machinery in practice.

Dear readers, I believe that also in this issue of Acta Mechanica Slovaca you will find much new information and inspiration for your scientific and research work. 